\title{
Synthesis and Physicochemical Properties of Yttrium Oxide Doped with Neodymium and Lanthanum
}

\author{
A. KRUK, ${ }^{1}$ M. MRÓZEK, ${ }^{2}$ J. DOMAGAłA, ${ }^{1}$ T. BRYLEWSKI,${ }^{1,3}$ \\ and W. GAWLIK ${ }^{2}$ \\ 1.-AGH University of Science and Technology, Faculty of Materials Science and Ceramics, \\ Al. Mickiewicza 30, 30-059 Krakow, Poland. 2.-Faculty of Physics, Astronomy and Applied \\ Computer Science, Jagiellonian University, ul. Reymonta 4, 30-059 Kraków, Poland. 3.-e-mail: \\ brylew@agh.edu.pl
}

\begin{abstract}
Transparent $\mathrm{La}_{0.1} \mathrm{Nd}_{0.1} \mathrm{Y}_{1.8} \mathrm{O}_{3}$ ceramics were prepared by use of the ethylenediaminetetraacetic acid gel process followed by sintering by hot isostatic pressing. The structure and morphology of the powders and bulk samples and the optical properties of bulk samples were investigated by use of x-ray diffraction (XRD), scanning electron microscopy, visible and near-infrared reflectance spectroscopy, and study of magneto-optic (Faraday) effects. The powders consisted of many agglomerates of fine, oval particles. XRD studies of the powder and bulk sample confirmed their single-phase composition, and spectrophotometric and magneto-optical studies in the range 500-1000 nm revealed their potential for application as an optical materials.
\end{abstract}

Key words: Transparent ceramics, optical properties, microstructure, $\mathrm{Y}_{2} \mathrm{O}_{3}$, wet chemistry, preparation

\section{INTRODUCTION}

In the quest for materials with specially designed optical properties, the attention of materials researchers has become increasingly focused on a variety of transparent ceramics. These materials are extremely hard and heat-resistant, and often have very interesting optical properties. One such material is polycrystalline yttrium oxide, $\mathrm{Y}_{2} \mathrm{O}_{3}$. Its main advantages include a high melting point, ca $2450^{\circ} \mathrm{C}$, good chemical stability, satisfactory mechanical properties, and a low coefficient of thermal expansion. These features make it a good candidate for application as a material for sight glasses operating at high temperatures and in aggressive environments. 1,2 An important property of this material is its transparency, which may be as high as $70 \%$ for visible light and approximately $60 \%$ for infrared light. ${ }^{3}$ This high transparency, low cutoff energy of phonons, and the ease with which rare earth elements can be incorporated into the $\mathrm{Y}_{2} \mathrm{O}_{3}$ lattice, make transparent yttrium oxide an excellent

(Received November 15, 2013; accepted May 13, 2014; published online June 12, 2014) material for manufacturing neodymium Nd:YAG lasers, in which the appropriate quantum transitions are mediated by neodymium ions. ${ }^{4}$ Semiconductor components of $\mathrm{MOS}^{5}$ and $\mathrm{LED}^{6}$ transistors are another popular application of $\mathrm{Y}_{2} \mathrm{O}_{3}$.

A $\mathrm{Y}_{2} \mathrm{O}_{3}-\mathrm{ThO}_{2}$ system with transmission above $70 \%$ was obtained in the 1970 s. $^{7}$ However, this first composite did not find widespread application, because it required sintering at very high temperatures, ca $2000-2200^{\circ} \mathrm{C}$. In recent years, attempts have been made to develop new materials with high Verdet constants for applications as optical isolators, devices consisting of a light polarizer and a material placed in a magnetic field. The specific nature of the Faraday effect and appropriate arrangement of the light polarizers result in unidirectional light transmission by such devices: light is transmitted in one direction but blocked in the opposite direction. The main criterion when choosing a material suitable for such application is a sufficiently high Verdet constant. ${ }^{8,9}$

In this paper we describe an attempt to prepare micropowders of composition of $\mathrm{La}_{0.1} \mathrm{Nd}_{0.1} \mathrm{Y}_{1.8} \mathrm{O}_{3}$ for possible application as transparent bulk samples. Results obtained from physicochemical evaluation 
of the ceramics and from optical and magneto-optical measurements show their potential for future application as optical materials.

\section{EXPERIMENTAL}

\section{Sample Preparation}

The method of preparation chosen for synthesis of $\mathrm{La}_{0.1} \mathrm{Nd}_{0.1} \mathrm{Y}_{1.8} \mathrm{O}_{3}$ powder was the ethylenediaminetetraacetic acid (EDTA) gel technique; this method is especially useful for this compound because of the high conditional stability constant of the complexes of EDTA anions with $\mathrm{La}, \mathrm{Nd}$, and $\mathrm{Y}$ ions. ${ }^{10}$ As described in detail in Ref. 11, the concept of EDTA gel processes, i.e. processes based on water-soluble metal chelates, is to reduce the concentration of free-metal ions in the precursor solution by formation of strong, soluble chelate complexes which are subsequently converted into an amorphous glassy state when the solvent is removed.

For preparation of the EDTA gel precursor, lanthanum(III) nitrate hexahydrate $\mathrm{La}\left(\mathrm{NO}_{3}\right)_{3} \cdot 6 \mathrm{H}_{2} \mathrm{O}$ (Sigma-Aldrich; 99.9\%), neodymium(III) nitrate hexahydrate $\mathrm{Nd}\left(\mathrm{NO}_{3}\right)_{3} \cdot 6 \mathrm{H}_{2} \mathrm{O}$ (Sigma-Aldrich; $\geq$ 99.9\%), and yttrium(III) nitrate hexahydrate $\mathrm{Y}\left(\mathrm{NO}_{3}\right)_{3} \cdot 6 \mathrm{H}_{2} \mathrm{O}$ (Sigma-Aldrich; $99.8 \%$ trace metals basis) as starting materials and ethylenediaminetetraacetic acid $\left(\mathrm{C}_{10} \mathrm{H}_{16} \mathrm{~N}_{2} \mathrm{O}_{8}\right.$, Aldrich; $\left.99.995 \%\right)$ as chelating agent were used as received from the suppliers.

Salts with known dry matter content were used for preparation of $1.0 \mathrm{M}\left(1.0 \mathrm{~mol} \mathrm{dm} \mathrm{dm}^{-3}\right) \mathrm{La}, \mathrm{Nd}$, and Y nitrate solutions, which were subsequently mixed in the appropriate ratio to yield the desired stoichiometry. The nitrate solution was mixed with $0.1 \mathrm{M}$ EDTA acid in the ratio $1 \mathrm{~mol}$ EDTA acid per 1 mol metal cations). Constant $\mathrm{pH} 8$ was maintained by dropwise addition of aqueous ammonia solution by use of a peristaltic pump.

The aqueous solution containing lanthanum, neodymium, and yttrium complexes was slowly heated and stirred at $70-90^{\circ} \mathrm{C}$ to evaporate the water until a transparent, glassy gel was obtained. The gel precursor was then pyrolyzed at $600^{\circ} \mathrm{C}$ for $1 \mathrm{~h}$, crushed, and calcined at $700^{\circ} \mathrm{C}$ for $10 \mathrm{~h}$ in static air.

The resulting $\mathrm{La}_{0.1} \mathrm{Nd}_{0.1} \mathrm{Y}_{1.8} \mathrm{O}_{3}$ powder was ground in a rotary-vibratory mill in dry ethanol with a specific amount of poly(vinyl dichloride) (PVD) for $5 \mathrm{~h}$ then dried at room temperature. The powder was uniaxially dry-pressed in a steel die at $100 \mathrm{MPa}$ into cylindrical shapes with a diameter of $10 \mathrm{~mm}$ and a height of approximately $2 \mathrm{~mm}$, followed by isostatic pressing at $300 \mathrm{MPa}$. The pressed specimens were pre-sintered at $1600^{\circ} \mathrm{C}$ for $2 \mathrm{~h}$ in air, placed in a graphite crucible, and then sintered by use of the hot isostatic pressing (HIP) method in an EPSI (Engineered Pressure Systems, USA) furnace at $1700^{\circ} \mathrm{C}$, in argon under $400 \mathrm{MPa}$, for $2 \mathrm{~h}$.

\section{Methodology}

Simultaneous DTA/TG thermal analysis of the precursor gel was conducted by use of a Netzsch STA 449 F3 apparatus under the conditions: heating rate $5 \mathrm{~K} \mathrm{~min}^{-1}$, temperature range $25-1100^{\circ} \mathrm{C}$, atmosphere air, with alumina as reference.

An X'Pert XRD diffractometer (Panalytical) was used for phase analysis of the samples; $\mathrm{CuK}_{\alpha}$ radiation was used with scanning at $0.008^{\circ}$ per step. Qualitative phase analysis was performed by use of Highscore Plus software (Panalytical) and the standard data set of PCPDFWIN v.2.3. Unit cell parameters of the constituent phases were determined on the basis of the Rietveld profile refinement method. A software module for the Rietveld analysis was incorporated into the Highscore Plus software. The average crystallite size of the powder was calculated on the basis of XRD data and Scherrer's equation. ${ }^{12}$

Scanning electron microscopy (FEI Nova NanoSEM 200) coupled with an energy-dispersive x-ray analysis (EDAX) Genesis XM x-ray microanalysis system based on the EDAX Sapphire Si(Li) EDS detector were used to examine the morphology and chemical composition of the samples. For grain size and shape determination, samples were polished then thermally etched at $1500^{\circ} \mathrm{C}$ for $2 \mathrm{~h}$. To measure grain size, SEM images after binarization were processed by use of Image J 3.14 software.

The specific surface area of the powder was estimated by use of the BET with an ASAP $2010 \mathrm{v} 4.00$ $\mathrm{G}$ instrument. Its chemical composition was determined by means of atomic absorption spectroscopy (ASA) by use of a Pye Unicam SP90B spectrometer.

The carbon content of the powder was determined by use of a LECO SC-32 instrument. This method involves complete combustion of the samples in an oxygen stream at $1450^{\circ} \mathrm{C}$. The amount of carbon dioxide formed was determined by weighing using a steady-state infrared detector. The LECO SC-32 instrument enables determination of carbon content with an accuracy of $0.01 \mathrm{wt} . \%$ for a sample weighing $0.35 \mathrm{~g}$.

The relative density of the sintered samples was measured by means of the Archimedes method, using water as immersion medium.

The absorption coefficient of yttria ceramics was measured over the wavelength range 500-1000 nm by use of a visible and near-infrared (VIS/NIR) reflectance spectrometer (AvaSpec-ULS3648). The light source was an SL1 $12 \mathrm{~W}$ halogen lamp, capable of emission in the range 350-2200 $\mathrm{nm}$ (StellaNet). Sample thickness was $0.5 \mathrm{~mm}$.

Faraday effect measurements were obtained by use of the apparatus shown schematically in Fig. 1 . The field induction, $B$, could be adjusted by varying the distance between the magnets. For the measurements described, $B$ was set to $0.2 \pm 0.001 \mathrm{~T}$. To determine the dispersion of the Verdet constant, rather than single values only, four different 


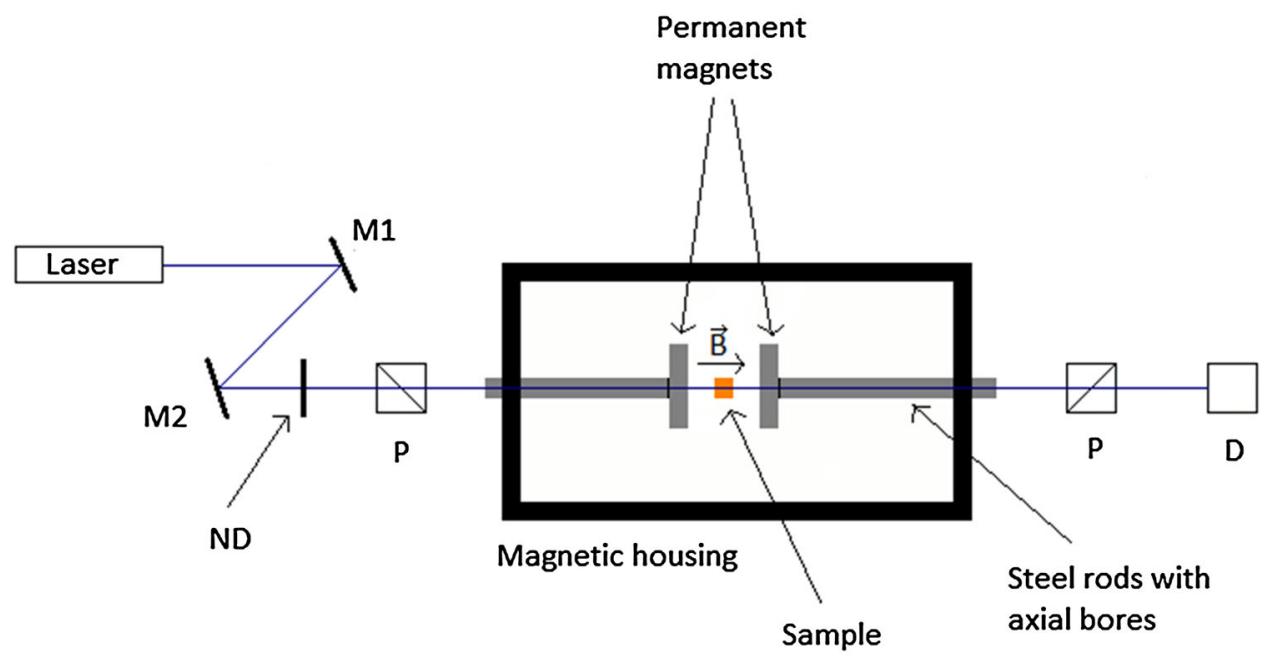

Fig. 1. Schematic diagram of the apparatus used for Faraday effect measurements (M1 and M2, mirrors; $P$, crystal linear polarizers; ND, neutral density filter; D, photodetector).

monochromatic light sources operating at different wavelengths were used: the second harmonic of the $532 \mathrm{~nm}$ Nd:YAG laser, a $633 \mathrm{~nm} \mathrm{He}-\mathrm{Ne}$ laser, and two diode lasers with wavelengths $780 \mathrm{~nm}$ and $809 \mathrm{~nm}$. The periscope arrangement facilitated easy exchange of individual lasers. The measurement procedure was based on recording the intensity of light transmitted by the sample placed between two crossed crystal polarizers $(\mathrm{P})$ in a given magnetic field. The light intensity was measured with a photodiode D (Thorlabs S120C) and calibrated with a power meter (Thorlabs PM100D). No modulation techniques were used in the experiment.

The method of measurement and the procedure used for data analysis will be described elsewhere. ${ }^{13}$ In short, the method takes into account the finite quality of the polarizers and the sample's attenuation/absorption. The measured values of the Verdet constant were determined on the basis of the relationship $V=\theta /(B \cdot S)$, where $\theta$ is the measured Faraday rotation angle $\left(^{\circ}\right), B$ is the magnetic field strength $(\mathrm{T})$, and $S$ is the sample length $(\mathrm{cm})$.

\section{RESULTS AND DISCUSSION}

\section{Powder Characteristics}

Differential thermal analysis (DTA) and thermogravimetric analysis (TG) were used to determine the optimum conditions for thermal decomposition of the gel precursor by calcination, which makes it possible to obtain a fully reacted powder with the desired phase and chemical composition and a finecrystalline structure which is maintained under a variety of conditions. Figure 2 shows the DTA and TG curves for the precursor gel obtained by use of the EDTA gel process. The TG curve is indicative of multistep decomposition behavior during thermal treatment of the precursor gel. Most of the weight loss occurs below $700^{\circ} \mathrm{C}$ and the total weight loss over this range is $89.0 \%$.

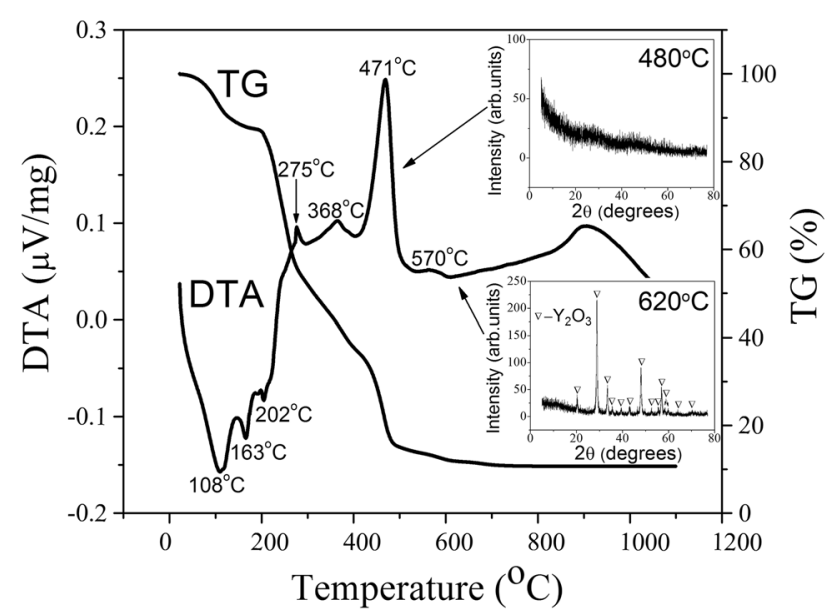

Fig. 2. DTA/TG thermal curves for the precursor gel obtained by use of the EDTA gel process. Inset: XRD patterns for the precursor heated for $15 \mathrm{~min}$ in air at 480 and $620^{\circ} \mathrm{C}$.

The three endothermic peaks observed in the DTA curve at 108,163 , and $202^{\circ} \mathrm{C}$, and the ensuing $13.1 \%$ reduction in weight, as indicated by the TG curve in the temperature range from $25^{\circ} \mathrm{C}$ to $260^{\circ} \mathrm{C}$, are attributed to removal of absorbed and molecular water. Gradual mass loss occurred from $260^{\circ} \mathrm{C}$ to $486^{\circ} \mathrm{C}$, with the total weight loss over this range equal to $45.0 \%$. This was accompanied by three exothermic peaks at 275,368 , and $471^{\circ} \mathrm{C}$ as a result of the combustion reaction between the rare earth nitrate and ethylenediaminetetraacetic acid (EDTA). Moreover, the presence of the small, broad exothermic peak at approximately $570^{\circ} \mathrm{C}$ indicates that decomposition of the precursor gel led to crystallization of the $\mathrm{La}_{0.1} \mathrm{Nd}_{0.1} \mathrm{Y}_{1.8} \mathrm{O}_{3}$ phase (Fig. 2). No evident weight loss at temperatures $>700^{\circ} \mathrm{C}$ indicates completion of the thermal decomposition of the precursor gel and the crystallization of the yttria. 
To confirm the crystallization temperature of the $\mathrm{La}_{0.1} \mathrm{Nd}_{0.1} \mathrm{Y}_{1.8} \mathrm{O}_{3}$ phase, $\mathrm{x}$-ray diffractograms were acquired for samples obtained at $480^{\circ} \mathrm{C}$ (before the crystallization peak at $570^{\circ} \mathrm{C}$ ) and $620^{\circ} \mathrm{C}$ (after the crystallization peak at $570^{\circ} \mathrm{C}$ ) after heating the precursor gel in air for $15 \mathrm{~min}$. The XRD results are presented in the insets in Fig. 2. The XRD pattern for the precursor heated at $480^{\circ} \mathrm{C}$ is indicative of a completely amorphous structure whereas that for the sample obtained after heating the precursor at $620^{\circ} \mathrm{C}$ contains peaks arising from the $\mathrm{Y}_{2} \mathrm{O}_{3}$ phase. Dong et al. ${ }^{14}$ had reported a crystallization temperature of $593^{\circ} \mathrm{C}$ for $\mathrm{La}_{0.1} \mathrm{Nd}_{0.1} \mathrm{Y}_{1.8} \mathrm{O}_{3}$ nanopowders synthesized by the combustion method with poly(ethylene glycol) (PEG) as dispersing agent and citric acid as combustion enhancer. This crystallization temperature was confirmed by x-ray diffraction (XRD) analysis of the precursor calcined in the temperature range $400-800^{\circ} \mathrm{C}$ for $2 \mathrm{~h}$ in air. The precursor calcined at $400^{\circ} \mathrm{C}$ was amorphous whereas at $600^{\circ} \mathrm{C}$ only the $\mathrm{Y}_{2} \mathrm{O}_{3}$ phase was present. The slight difference between the crystallization temperatures in this report and in Dong's paper ${ }^{14}$ may be attributed to the different procedures used for preparation of the precursor gel, and, hence, different chemical compositions of the precursor gels, and different heating rates used during DTA/ TG analysis.

On the basis of studies of the decomposition of the gel precursors, the optimum conditions for production of yttrium oxide doped with neodymium and lanthanum powder were determined. The optimum conditions for calcination were $700^{\circ} \mathrm{C}$ for $10 \mathrm{~h}$ in air. Taking into account the results from XRD analysis of the $\mathrm{La}_{0.1} \mathrm{Nd}_{0.1} \mathrm{Y}_{1.8} \mathrm{O}_{3}$ powder shown in Fig. 3, it may be concluded that the sample obtained under these conditions had the single-phase structure of $\mathrm{Y}_{2} \mathrm{O}_{3}$ (JCPDS card no. 83-0927), indicating formation of a

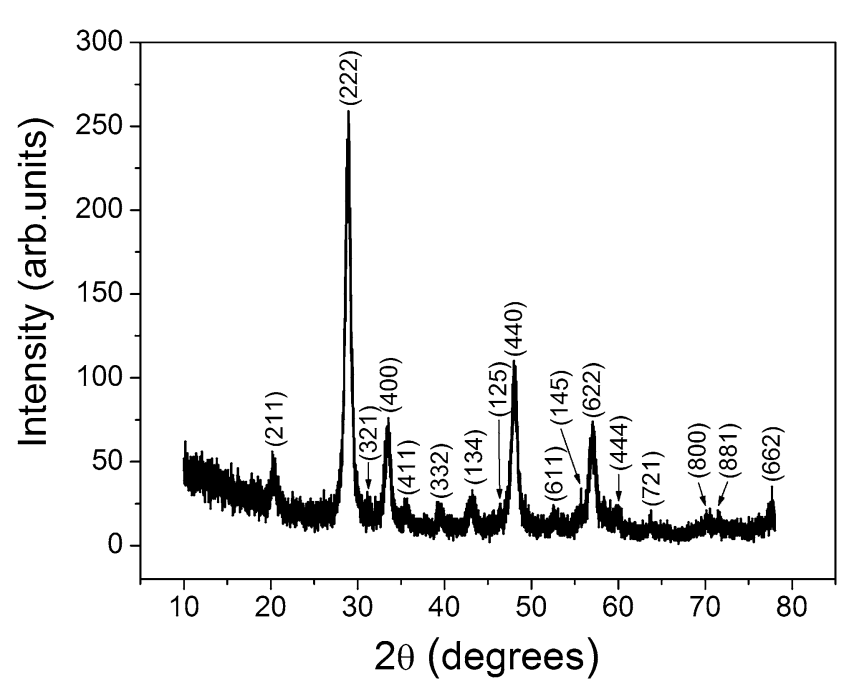

Fig. 3. XRD pattern of $\mathrm{La}_{0.1} \mathrm{Nd}_{0.1} \mathrm{Y}_{1.8} \mathrm{O}_{3}$ powder obtained by use of the EDTA gel process then calcination in air at $700^{\circ} \mathrm{C}$ for $10 \mathrm{~h}$. solid solution consisting of the $\mathrm{Y}_{2} \mathrm{O}_{3}$ matrix and $\mathrm{La}^{3+}$ and $\mathrm{Nd}^{3+}$ ions.

Rietveld analysis of the diffraction pattern indicates the presence of a cubic phase in the powder which seems to crystallize with the Ia-3 space group. The established value of the lattice parameter, $a=10.72044 \AA$, is higher than that observed for pure yttria $(10.6080 \AA$ ) because of the large ionic radii of $\mathrm{La}^{3+}(1.03 \AA)$ and $\mathrm{Nd}^{3+}(1.08 \AA)$ ions compared with the $\mathrm{Y}^{3+}(0.90 \AA)$ ion. ${ }^{15}$ By using the full width at half maximum (FWHM) of the broad peaks in Scherrer's equation, ${ }^{12}$ the average particle size was calculated to be $12 \mathrm{~nm}$ for fully crystalline $\mathrm{La}_{0.1} \mathrm{Nd}_{0.1} \mathrm{Y}_{1.8} \mathrm{O}_{3}$ powder.

To verify the level of deviations from nominal stoichiometry of $\mathrm{La}_{0.1} \mathrm{Nd}_{0.1} \mathrm{Y}_{1.8} \mathrm{O}_{3}$ powder calcined
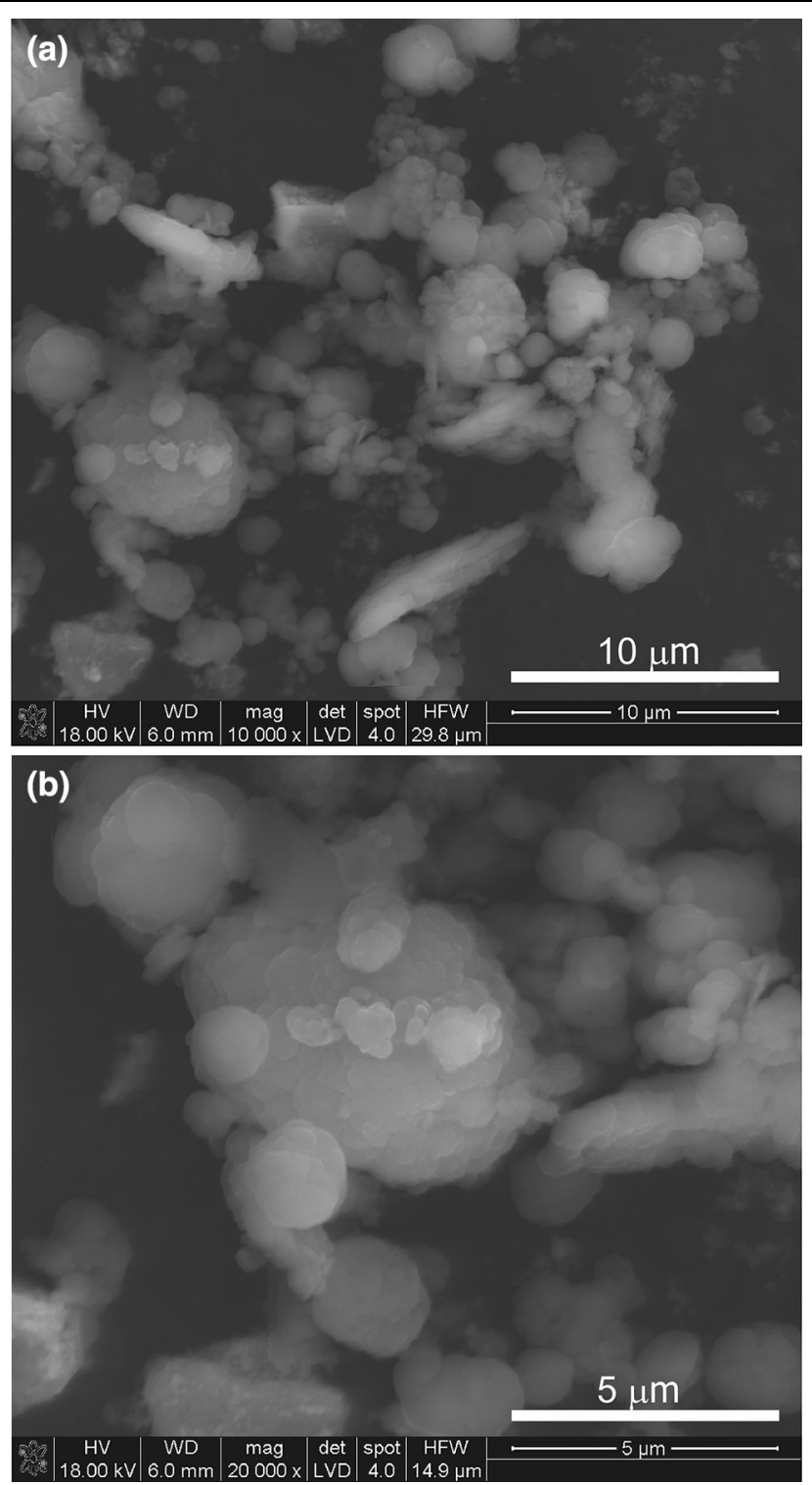

Fig. 4. SEM microphotograph of $\mathrm{La}_{0.1} \mathrm{Nd}_{0.1} \mathrm{Y}_{1.8} \mathrm{O}_{3}$ powder obtained by use of the EDTA gel process then calcination in air at $700^{\circ} \mathrm{C}$ for 10 h. Magnification: (a) $\times 10,000$; (b) $\times 20,000$. 
for $10 \mathrm{~h}$ in air at $700^{\circ} \mathrm{C}$, its chemical composition was analyzed by means of ASA. It was found that the powder had a molar La:Nd:Y ratio of 0.09:0.12:1.79. This indicates that the molar ratios of these elements corresponded approximately to the assumed stoichiometric composition.

During heat-treatment the precursor gel emits hydrocarbons, especially in the initial stage of its thermal decomposition. The presence of carbon in its free form during the subsequent stage of sample synthesis may result in deterioration of the optical properties of transparent ceramics because of its accumulation in the intergranular regions. Analysis of the powder after calcination in air at $700^{\circ} \mathrm{C}$ for $10 \mathrm{~h}$ indicated the carbon content was low, $0.14 \pm 0.03$ wt.\%. Thus, use of the EDTA gel process
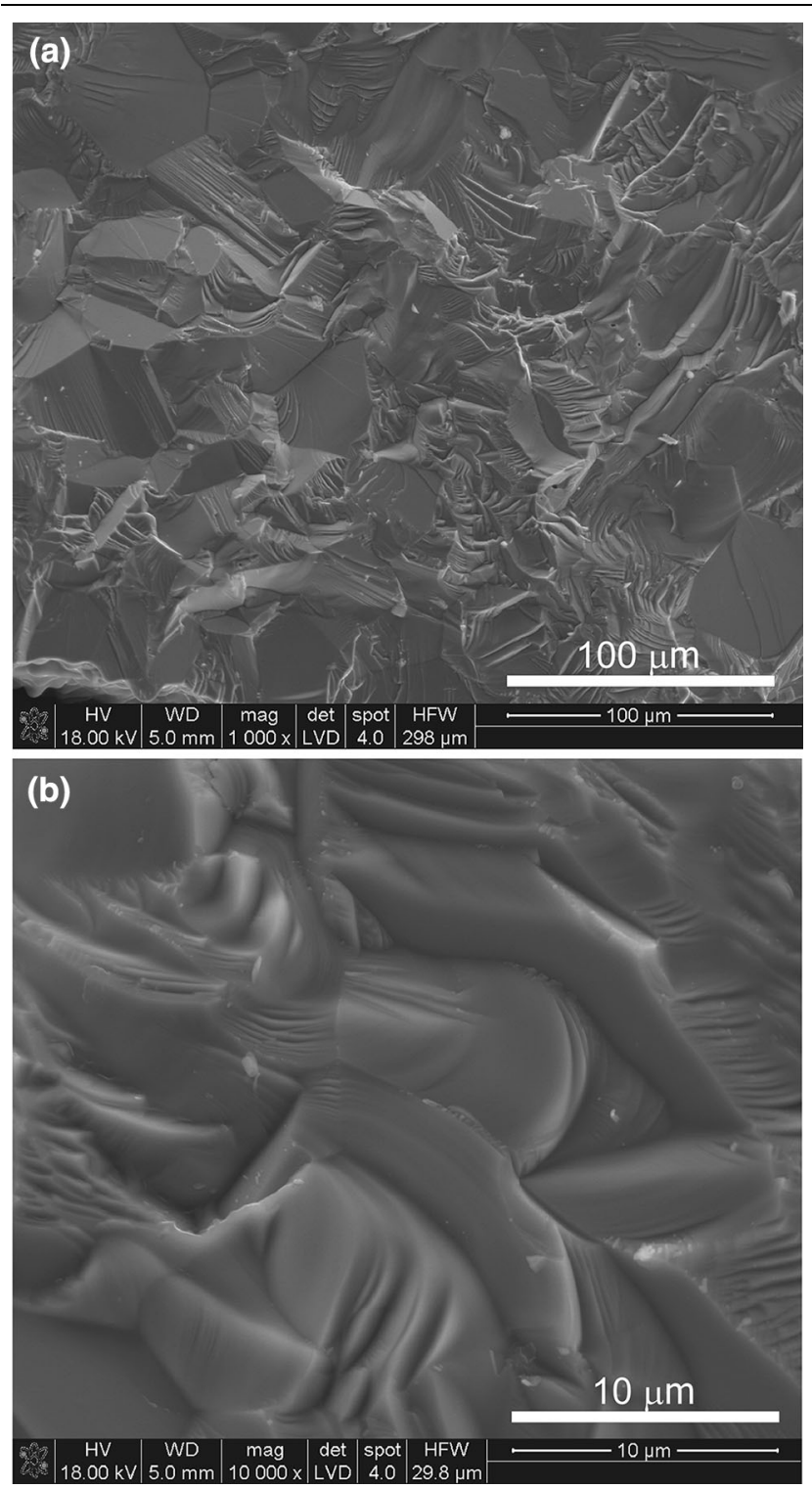

Fig. 5. SEM photograph of the surface of a fracture of $\mathrm{La}_{0.1} \mathrm{Nd}_{0.1}$ $\mathrm{Y}_{1.8} \mathrm{O}_{3}$ bulk sample sintered for $2 \mathrm{~h}$ in argon at $1700^{\circ} \mathrm{C}$ by use of $\mathrm{HIP}$. Magnification: (a) $\times 1000$ and (b) $\times 10,000$. in combination with appropriate heat treatment yielded fully reacted and practically carbon-free $\mathrm{La}_{0.1} \mathrm{Nd}_{0.1} \mathrm{Y}_{1.8} \mathrm{O}_{3}$ powder at the relatively low temperature of $700^{\circ} \mathrm{C}$.

To obtain information about the shape and size of the particles of the powder, its morphology was studied by use of SEM. An SEM microphotograph of $\mathrm{La}_{0.1} \mathrm{Nd}_{0.1} \mathrm{Y}_{1.8} \mathrm{O}_{3}$ powder calcined for $10 \mathrm{~h}$ in air at $700^{\circ} \mathrm{C}$ is presented in Fig. 4 .

From these observations it can be concluded that the synthesized powder is very fine and agglomerated in nature, because of the high surface energy of its particles. The agglomerates are oval in shape, with an average size of $0.6-2.8 \mu \mathrm{m}$ (Fig. 4). The BET surface area, $3.36 \pm 0.01 \mathrm{~m}^{2} \mathrm{~g}^{-1}$, reflected the finegrained nature of the $\mathrm{La}_{0.1} \mathrm{Nd}_{0.1} \mathrm{Y}_{1.8} \mathrm{O}_{3}$ powder.

\section{Bulk Sample Characteristics}

An XRD study of the $\mathrm{La}_{0.1} \mathrm{Nd}_{0.1} \mathrm{Y}_{1.8} \mathrm{O}_{3}$ bulk sample obtained from powder synthesized by use of the EDTA gel process then sintering by means of hot isostatic pressing (HIP) for $2 \mathrm{~h}$ in argon at $1700^{\circ} \mathrm{C}$ confirmed its single-phase composition of $\mathrm{Y}_{2} \mathrm{O}_{3}$ with a cubic structure. Its lattice parameter was determined to be $10.69594 \AA$.

Figure 5 shows the surface morphology of a fracture of the $\mathrm{La}_{0.1} \mathrm{Nd}_{0.1} \mathrm{Y}_{1.8} \mathrm{O}_{3}$ bulk sample sintered by use of the HIP method. The microstructure was extremely dense, with hardly any pores in or between the grains. The grain boundaries were sharply defined, and the size of fully grown grains was in the range 15-100 $\mu \mathrm{m}$, as shown in an SEM image of the polished and thermally etched surface of the sample (Fig. 6). The relative density of the ceramics was approximately $99.4 \pm 0.7 \%$.

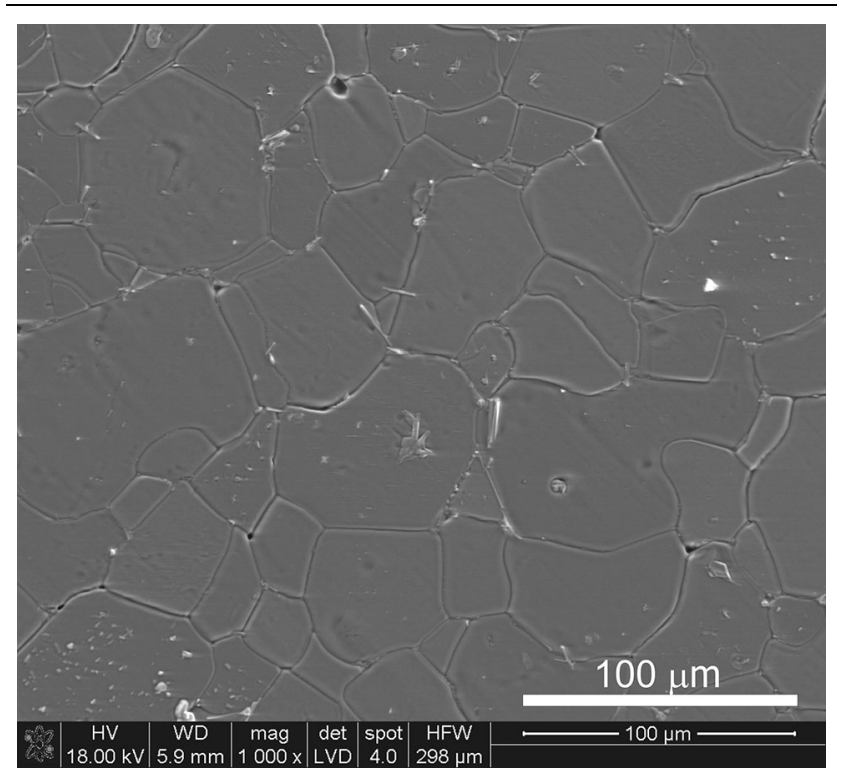

Fig. 6. SEM photograph of the polished and thermally etched surface of $\mathrm{La}_{0.1} \mathrm{Nd}_{0.1} \mathrm{Y}_{1.8} \mathrm{O}_{3}$ bulk sample sintered for $2 \mathrm{~h}$ in argon at $1700^{\circ} \mathrm{C}$ by use of HIP (magnification $\times 1000$ ). 


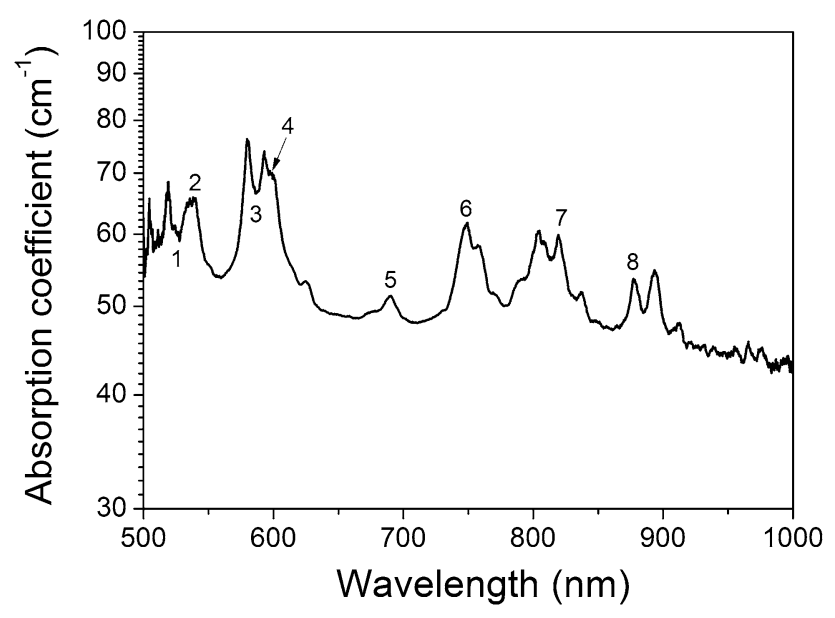

Fig. 7. Optical absorption coefficient of $\mathrm{La}_{0.1} \mathrm{Nd}_{0.1} \mathrm{Y}_{1.8} \mathrm{O}_{3}$ bulk sample sintered for $2 \mathrm{~h}$ in argon at $1700^{\circ} \mathrm{C}$ by use of HIP.

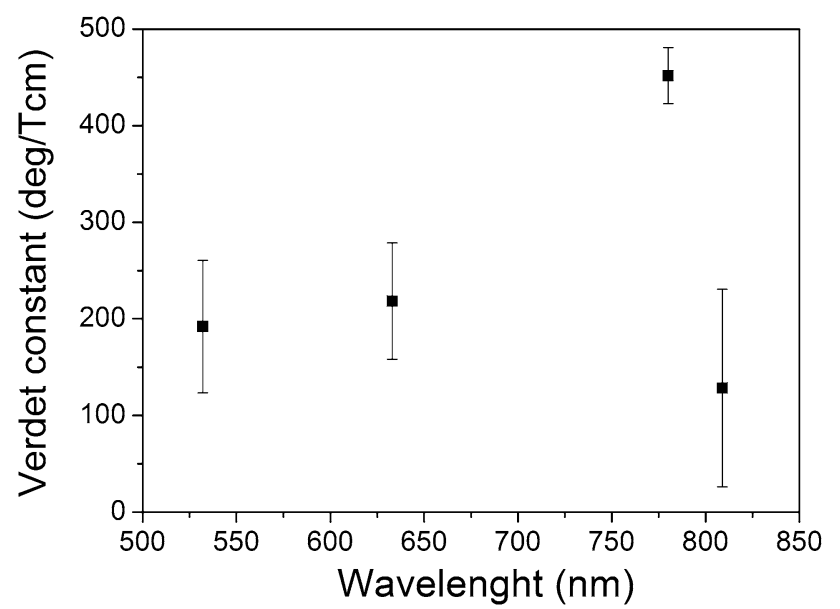

Fig. 8. Verdet constants of $\mathrm{La}_{0.1} \mathrm{Nd}_{0.1} \mathrm{Y}_{1.8} \mathrm{O}_{3}$ bulk sample sintered for $2 \mathrm{~h}$ in argon at $1700^{\circ} \mathrm{C}$ by use of HIP, presented as a function of wavelength.

Semiquantitative elemental EDAX analysis performed on coarse crystalline grains yielded average La:Nd:Y ratios of approximately $0.08: 0.11: 1.81$, in approximate agreement with the overall composition of the $\mathrm{La}_{0.1} \mathrm{Nd}_{0.1} \mathrm{Y}_{1.8} \mathrm{O}_{3}$ sintered ceramics.

Light transmittance is the main optical property considered when evaluating transparent ceramics. The maximum transmission of a $0.5 \mathrm{~mm}$ thick $\mathrm{La}_{0.1} \mathrm{Nd}_{0.1} \mathrm{Y}_{1.8} \mathrm{O}_{3}$ bulk sample, sintered for $2 \mathrm{~h}$ in argon at $1700^{\circ} \mathrm{C}$ by use of the HIP method, was $7 \%$ at $1000 \mathrm{~nm}$.

Figure 7 shows the absorption coefficient spectrum of this sample in the wavelength range 500$1000 \mathrm{~nm}$. It is apparent there are several groups of absorption peaks. Peaks occurring at 525, 540, 582, $596,690,748,820$, and $878 \mathrm{~nm}$ correspond to the following optical transitions in the $\mathrm{Nd}^{3+}$ ion energy level system: ${ }^{4} \mathrm{I}_{9 / 2} \rightarrow{ }^{4} \mathrm{G}_{7 / 2}$ (band 1 ); ${ }^{4} \mathrm{G}_{7 / 2} \rightarrow{ }^{2} \mathrm{~K}_{13 /}$ ${ }_{2}$ (band 2); ${ }^{4} \mathrm{I}_{9 / 2} \rightarrow{ }^{4} \mathrm{G}_{5 / 2}$ (band 3 ); ${ }^{4} \mathrm{G}_{5 / 2}$ (band 4);
${ }^{4} \mathrm{I}_{9 / 2} \rightarrow{ }^{4} \mathrm{~F}_{9 / 2}$ (band 5); ${ }^{4} \mathrm{I}_{9 / 2} \rightarrow{ }^{4} \mathrm{~F}_{7 / 2}+{ }^{4} \mathrm{~S}_{3 / 2}$ (band 6); ${ }^{4} \mathrm{I}_{9 / 2} \rightarrow{ }^{2} \mathrm{H}_{9 / 2}+{ }^{4} \mathrm{~F}_{5 / 2}$ (band 7) and ${ }^{4} \mathrm{I}_{9 / 2} \rightarrow{ }^{4} \mathrm{~F}_{3 / 2}$ (band 8). 3,16

Figure 8 shows results from Verdet constant measurements at four different wavelengths. $\mathrm{La}_{0.1} \mathrm{Nd}_{0.1} \mathrm{Y}_{1.8} \mathrm{O}_{3}$ has a large Verdet constant. Interestingly, it increases with increasing wavelength.

\section{CONCLUSIONS}

The EDTA gel process was used for synthesis of $\mathrm{La}_{0.1} \mathrm{Nd}_{0.1} \mathrm{Y}_{1.8} \mathrm{O}_{3}$ powder. The powder obtained consisted of well-developed agglomerates of fine grains with the shape of oval platelets. XRD studies confirmed the single-phase composition of the powder, which indicated incorporation of neodymium and lanthanum into the crystal lattice of the yttria. Study of the morphology of sintered $\mathrm{La}_{0.1} \mathrm{Nd}_{0.1} \mathrm{Y}_{1.8} \mathrm{O}_{3}$ powder obtained by hot isostatic pressing (HIP) revealed the presence of grains with regular shape, well-defined boundaries, and no visible pores.

The optical properties were measured in between 500 and $1000 \mathrm{~nm}$ and Verdet constants were measured at four specific wavelengths, 532, 633, 780, and $809 \mathrm{~nm}$. The accuracy of measurement of Verdet constants was reduced by the rather low transmission $(7 \%)$ of the sample but the high values obtained $\left(>172^{\circ} / \mathrm{T} \mathrm{cm}\right)$ were indicative of the high potential of the material for use as a good optical isolator.

\section{ACKNOWLEDGEMENTS}

The authors would like to express their gratitude to Professor M. Bućko from the Faculty of Materials Science and Ceramics, AGH University of Science and Technology, Krakow, for allowing us to study the process of sintering of the samples by HIP. The authors are also indebted to Dr. A. Adamczyk from the Faculty of Materials Science and Ceramics, AGH University of Science and Technology, Krakow, for her assistance with XRD analysis. MM and WG are grateful for support from the ATOMIN Project (POIG 02.01.00-12-023/08).

\section{OPEN ACCESS}

This article is distributed under the terms of the Creative Commons Attribution License which permits any use, distribution, and reproduction in any medium, provided the original author(s) and the source are credited.

\section{REFERENCES}

1. H. Eilers, J. Eur. Ceram. Soc. 27, 4711 (2007).

2. A. Wajler, H. Węglarz, H. Tomaszewski, M. Możdżonek, A. Sidorowicz, and Z. Librant, Ceram. Mater. 64, 108 (2012).

3. X. Hou, S. Zhou, T. Jia, H. Lin, and H. Teng, J. Lumin. 131, 1953 (2011)

4. A. Shirakawa, K. Takaichi, H. Yagi, J.F. Bisson, J. Lu, M. Musha, K. Ueda, T. Yanagitani, T. Petrov, and A. Kaminskii, Opt. Express 11, 2911 (2003). 
5. K.J. Hubbard and D.G. Schlom, J. Mater. Res. 11, 2757 (1996),

6. A. Gajović, N. Tomašić, I. Djerdj, D.S. Su, and K. Furić, J. Alloys Compd. 456, 313 (2008).

7. R.D. Anderson, US Patent 3545987 (1970).

8. J.-P. Castéra and G. Hepner, Appl. Opt. 16, 2031 (1977).

9. Proc. SPIE 1367, Fiber Optic and Laser Sensors VIII, 243 (1991).

10. K.S. Irani, A.P.B. Sinha, and A.B. Biswas, J. Phys. Chem. Solids 23, 711 (1962).

11. M. Kakihana, J. Sol Gel. Sci. Technol. 6, 7 (1996).
12. B.D. Culity and S.R. Stock, Elements of X-Ray Diffraction, 2nd ed. (Cambridge, MA: Addition-Wesley, 1978).

13. P. Nakielna and J. Czerwiec (Master thesis, Jagiellonian University, 2007).

14. L.M. Dong, Z.D. Han, Z. Wu, and X.Y. Zhang, Mater. Chem. Phys. 135, 575 (2012).

15. B. Antic, M. Mitric, and D. Rodic, J. Magn. Magn. Mater. 145, 349 (1995).

16. Z. Huang, W. Guo, Y. Liu, Q. Huang, F. Tang, and Y. Cao, Mater. Chem. Phys. 128, 44 (2011). 